\title{
UMA ARQUEOLOGIA DAS CIÊNCIAS HUMANAS: AS PALAVRAS E AS COISAS
}

\author{
AN ARCHAEOLOGY OF HUMANITIES: THE ORDER OF THINGS
}

Guaracy Bolivar Araújo Mendes Júnior*

\section{RESUMO}

O artigo pretende apresentar elementos decisivos da arqueologia das ciências humanas proposta por Michel Foucault em As palavras e as coisas (1966). Tendo como ponto de partida uma caracterização da noção foucaultiana de saber (savoir), o artigo pretenderá qualificar o empreendimento arqueológico que define os trabalhos de Foucault durante os anos sessenta do século XX. Este mesmo projeto será analisado em maior detalhe a partir da obra que o celebrizou: As palavras e as coisas. Tomando como ponto de partida uma avaliação da noção central de epistêmé, o artigo apresenta uma descrição das principais articulações histórico-conceituais desta obra. Especial atenção será assim dedicada a dois pontos cruciais para o encaminhamento conceitual dado por Foucault. Em primeiro lugar, levantaremos a análise do autor acerca das condições históricas, materiais e epistêmicas que levaram ao surgimento das Ciências Humanas. Em segundo lugar, apresentaremos e discutiremos as teses propostas por Foucault diante da mais polêmica temática assumida em As palavras e as coisas: a saber, a caracterização foucaultiana da "morte do homem". Ao final, nos proporemos a discutir os méritos da polêmica em torno da noção de "morte do homem", assim como a avaliar as possibilidades abertas para o pensamento contemporâneo pelo projeto da arqueologia foucaultiana.

PALAVRAS-CHAVE: Foucault. Arqueologia. Saber. Episteme. Morte do homem

\section{ABSTRACT}

These article intents to expose decisive elementos of the archaelogy of the human scientes proposed by Michel Foucault in "The Order of Things" (1966). Having as a starting point a characterization of the foucauldian notion of knowledge (savoir) the article will qualify the archaelogical enterprise that defines Foucault's work during the sixties. Those same project

\footnotetext{
${ }^{*}$ Mestre em Filosofia (UFMG) e Doutorando em Filosofia (UFRJ). Professor do Curso de Filosofia da PUC Minas. E-mail: guaraciaraujo@ hotmail.com.
} 
will be analised in detail taking as reference the major work produced by Foucault in those years: "The Order of Things". Taking as a starting point an evaluation of the core notion of epistêmé the article presents a description of the major point indicated in the book in a historical and conceptual level. Close reading will be dedicated to two crucial aspects of the conceptual way deployed by Foucault. Firstly the analysis have as its focus the historical, material and epistemic conditions that defined the emergence of the Human Sciences. Secondly we will present and discuss the thesis proposed by Foucault about the most polemic theme assumed in "The Order of Things": the foucauldian characterization of the "death of the Man”. On the final considerations the article will deal with the scope and value of the socalled "death of Man" theme. At these moment we propose an evaluation concerning the possibilities opened by the archaeological project designed by Foucault in the context of the contemporary thought.

KEYWORDS: Foucault. Archeology. To know. Episteme. Death of man.

Desde o seu lançamento em 1966, no auge da voga estruturalista que atravessava um amplo conjunto de propostas e discussões atinentes às ciências humanas, As palavras e as coisas terá sido talvez o livro mais polêmico deste período. Embora os focos desta polêmica sejam diversificados, pode-se dizer que a mais controvertida e rumorosa de suas teses é aquela que se propõe em suas últimas páginas: fala-se aqui da morte do homem.

Parece natural supor que, no conhecimento humano desde a Antiguidade, o homem seja tematizado e que sempre o será, enquanto sujeito a partir do qual o conhecimento seria como que derivado; em particular, é bem conhecida a crença que afirma que, a partir do Renascimento, o homem teria ocupado posição central no campo da produção de conhecimentos. Poderíamos qualificar tal perspectiva como "humanismo"; ela se encontra distribuída em um sem-número de orientações teóricas com as quais Foucault se defrontou a partir dos anos sessenta (a fenomenologia, o existencialismo, o marxismo, dentre outros).

Afirmações ainda mais antigas e célebres, cuja proveniência parece contemporânea do próprio surgimento do pensamento ocidental, e que teriam sido constantes em seu caminhar, parecem supor a existência inconteste de um vínculo constante entre o conhecimento e o ser, entre as palavras e as coisas - quer seja esse vínculo imediatamente dado na experiência 
sensível, quer ainda mediado por representações, por fim orientado pela luz de um sujeito soberano.

Foucault mostrará em sua arqueologia do saber - ao menos desde $O$ nascimento da clínica (1963) - que o conhecimento e os seres nutrem relações diferenciais e transformáveis, que o vínculo entre palavras e coisas está subordinado a um nível anterior no qual se distribuem suas relações e eventuais privilégios. Como, em um momento determinado, se organizou esta relação? Como esta organização pode ser descrita, mapeada, e como a partir de suas dificuldades e limites esboçou-se e formou-se uma nova organização que, em algum momento, destronou a precedente? Estas são as perguntas cruciais que a arqueologia foucaultiana do saber pretende responder.

No entanto, devemos evitar supor que tal descrição pretenda esgotar o campo de tudo o que pode ser nomeado como saber. Lembramos aqui que a noção proposta por Foucault de saber aponta para um campo vasto e heterogêneo. São saberes as ciências, mas há também o saber em regulamentos e discursos políticos, em mapas, imagens e poemas. O projeto implicado por tal arqueologia não visa a nenhuma "arkhê", a nenhum princípio universal ordenador de todos os discursos possíveis; ao contrário (e esta parece ser uma das mais freqüentes incompreensões que cercaram este projeto de Foucault), as análises arqueológicas desenvolvem-se sempre em campos de saber delimitados, específicos, e são orientados por interrogações igualmente específicas.

No caso de As palavras e as coisas a preocupação do autor pode ser vista desde o título da obra: trata-se de uma arqueologia das ciências humanas. Um dos objetivos deste trabalho é apontar que, implícita ou explicitamente, esta preocupação estrutura toda a obra, orientando seu recorte e inviabilizando a suposição de que Foucault estaria a tratar do campo do saber em toda a sua abrangência. Igualmente, a demarcação suscitada pela problemática das ciências humanas também poderá explicar a insistência - assim como a pertinência - da temática foucaultiana da morte do homem, tão mal-interpretada e criticada.

Uma descrição sumária de As palavras e as coisas pode ser feita como se segue. Nesta obra Foucault supõe a existência de três grandes organizações do saber, três formas diferentes de distribuição entre palavras e coisas, três grandes conjuntos de condições de possibilidade histórica (o que Foucault chama de "a priori histórico") que podem ser deduzidos uma vez que se tome como orientação a seguinte pergunta: qual é o estatuto dado ao ser humano neste contexto de pensamento? Tais conjuntos são denominados por Foucault epistémês. Elas se 
localizam em um espaço intermediário, e supostamente fundamental: aquele que se dispõe entre, de um lado, as "ordens empíricas" das práticas, dos ritos, das formas de percepção, e de outras teorias, ciências, filosofias válidas em um determinado período. A epistémê é o lugar no qual surgem as orientações que, ao mesmo tempo, direcionam e criticam a vida prática e dão a base, o solo, de onde as teorias podem partir.

No entanto, ao selecionar três epistémês entre tantas outras possíveis (afinal, poderíamos perguntar: o que foi feito com o saber da antiguidade, da época medieval?), Foucault deixa claro o destino desta noção. Ela pretende servir como instrumento conceitual que viabiliza a crítica a uma posição humanista que não faz mais que considerar como antropologicamente orientado todo o conhecimento surgido a partir do Renascimento. Contra tal posição, argumentar-se-á que o homem, enquanto figura organizadora do saber, só surge em idade bem recente, a partir de fins do século XVIII.

Com efeito, na primeira destas epistémês - aquela que corresponde ao período renascentista, e que teria sido deslocada a partir do século XVII, a figura do homem será delineada no espaço de um saber que tem seu desenho dado pela categoria fundamental da semelhança. O saber renascentista move-se através de um circuito de noções aparentadas à semelhança - dentre as quais são destacadas a conveniência, a emulação, a analogia, e o par simpatia-antipatia, que, remetendo-se umas às outras incessantemente, formulam as condições para um saber circular e autorreferencial. O que tornará esta disposição ainda mais manifesta é a noção organizadora de assinalação, que aponta o remetimento recíproco de todas as ordens de seres, vistos como marcas e signos de outros seres que lhe são relacionados a partir das noções levantadas acima. Tal disposição é sugerida ainda por uma noção que parece ser a imagem privilegiada do espaço configuracional próprio a esta epistémê: a noção de cosmo.

Dentro desta epistémê, o homem pode aparecer no máximo como objeto e análogon privilegiado requerido constantemente no circuito demarcado pela semelhança ao qual todavia o homem, ser entre os seres, se submete.

Não será ainda o homem que orientará a nova configuração da epistémê surgida a partir do século XVII e que terá em Descartes sua figura paradigmática. Nesta perspectiva, o pensamento cartesiano representaria a falência da categoria e da configuração de saber engendrada a partir da categoria de semelhança, ao requerer um patamar de analiticidade e de ordenação frente ao qual a semelhança parece antes acarretar uma confusão, uma mistura permanente dos seres e dos conceitos. 
Uma citação nos colocará no centro da epistémê clássica:

[...] a epistémê clássica pode se definir, na sua mais geral disposição, pelo sistema articulado de uma máthesis, de uma taxinomia e de uma análise genética. As ciências trazem sempre consigo o projeto, mesmo longínquo, de uma exaustiva colocação em ordem: apontam sempre para a descoberta de elementos simples e de sua composição progressiva; e, no meio deles, elas formam quadro, exposição de conhecimentos, num sistema contemporâneo de si próprio. O centro do saber, nos séculos XVII e XVIII, é o quadro. Quanto aos grandes debates que ocuparam a opinião, alojam-se muito naturalmente nas dobras dessa organização. (FOUCAULT, 1981, p. 103).

\section{II}

Não se pretende aqui recuperar em profundidade a ampla descrição feita por Foucault do saber clássico, que ocupa grande parte de As palavras e as coisas. Pretendemos destacar apenas alguns aspectos, cruciais para o entendimento da epistémê que virá em seguida. Em primeiro lugar, o período clássico é dominado pela representação enquanto instância privilegiada do conhecimento: o que se quer ordenar de forma metódica e cada vez mais generalizada são as representações, vistas como o próprio elemento que se dá ao conhecimento. Assim, pode-se entender a caracterização frequente deste saber como analítico; a ordenação das representações se dá a partir do mais simples, no rumo do mais complexo, de forma contínua.

Seguindo essa linha geral, Foucault assumirá como dimensões privilegiadas da análise conhecimentos como a Historia natural (quadro ordenado dos seres, que procede a partir de uma ordenação em termos de identidades que vão sendo graduadas a partir de pequenas diferenças), a Análise das Riquezas (que busca saber como e porque determinada coisa adquire, é representada como tendo um certo valor) e a Gramática Geral (que analisa os signos linguísticos enquanto representações verbais), assim como filosofias como a dos Ideólogos (que teriam formulado uma teoria geral das representações).

Deve-se reparar todavia que, neste espaço de saber no qual representações respondem imediatamente aos seres, o homem não é uma figura determinante. Foucault fundamentará tal afirmação apontando a relação estabelecida neste período entre as noções de natureza e natureza humana; se o ser humano pode ser considerado como tendo certos privilégios enquanto ser que conhece, ele não deixa de estar preso ao grande quadro disposto pelo criador e no qual ele é apenas uma figura entre outras. As colocações de Gilles Deleuze (1995) sobre 
esse ponto são particularmente felizes: “[...] na formação histórica clássica, as forças no homem entram em relação com forças de fora de tal modo que o composto é a forma-Deus, nunca uma forma-Homem. Esse é o mundo da representação infinita” (DELEUZE, 1995, p. 134).

A passagem à epistémê moderna pode ser assinalada tanto no campo da filosofia, a partir do criticismo kantiano (do momento em que este subordina as representações ao sujeito do conhecimento), quanto, mais claramente, nas disciplinas anteriormente elencadas (história natural, análise das riquezas, gramática geral). Tal passagem pode ser nomeada como uma "torção a partir da historicidade". Em outros termos, objetos que se distribuíam no grande quadro plano das representações agora se torcem em si mesmos na medida em que passam a refletir a historicidade que os constituiria. Como apontam Dreyfus e Rabinow (1995), Foucault não tenta explicar tal "mutação arqueológica" por causas imanentes ao desenvolvimento ou progresso dos conhecimentos e das ciências; igualmente, não busca as causas da transformação em uma causalidade de cunho externo, no qual fatores sociais, políticos ou econômicos teriam dado as coordenadas para o surgimento de um novo tipo de saber. O autor não nega que as novas configurações das ciências específicas que surgem neste período possam ter sido impulsionadas por eventos históricos; apenas recusa uma causalidade externa para o conjunto da nova epistémê, na medida em que esta deve ser analisada de forma imanente (DREYFUS \& RABINOW, 1995, p. 30).

Um exemplo permite precisar melhor o que aconteceu: se a gramática geral era o patamar clássico para o estudo da linguagem, vista como suporte geral para todas as representações, o que ocorre agora é que os estudos de linguagem passam a revelar a historicidade constitutiva das línguas. É o surgimento, no vazio deixado pela epistémê anterior, da filologia, ciência que se dedicará inicialmente ao sistema regrado de transformações históricas das línguas. No seio deste saber, o homem se descobre como o sujeito privilegiado, como o próprio produtor do saber; no entanto, reconhece também que o objeto desta ciência é o próprio homem, enquanto ser que fala e utiliza a linguagem; reconhece ainda que, sendo aquele ser que constituiu em algum momento a linguagem, é todavia dominado por ela, na medida em que a linguagem necessariamente o antecede.

No saber moderno, tal como definido pelos novos saberes da vida, do trabalho e da linguagem (respectivamente: a biologia, a economia política, a filologia) o homem passa a ser sujeito e objeto do conhecimento; todavia, este duplo papel suscita uma percepção paradoxal 
do homem como ser que, ao mesmo tempo, domina e é dominado por aquilo que conhece. Ele se descobre como um ser cuja finitude é constituinte, embora esta se delineie sobre o fundo do indefinido. Por isso, Foucault sugere:

lá onde outrora havia correlação entre uma metafísica da representação e do infinito e uma análise dos seres vivos, dos desejos do homem, e das palavras de sua língua, vê-se constituir uma analítica da finitude e da existência humana, e em oposição a ela (mas numa oposição correlativa) uma perpétua tentação de constituir uma metafísica da vida, do trabalho e da linguagem. (FOUCAULT, 1981, p. 437).

Se tais metafísicas serão ao mesmo tempo barradas pela própria finitude que se constituiu no saber, esse limite dado à metafísica é, na opinião do autor, o correspondente negativo ao novo ser que passa a organizar em torno de si o saber: é o aparecimento do homem.

Foucault acredita, todavia, que não se trata de enxergar um súbito e misterioso aparecimento do homem como instância soberana do saber; trata-se de perceber que aquilo que remodelou por dentro o solo epistemológico foi o desnudamento da finitude e do circuito que esta engendra. A soberania do homem é fruto, muito mais, do espaço que lhe foi franqueado pela analítica da finitude. Tal analítica transcorre, como já se pode ver, no terreno da duplicidade; nela, vemos desenhar-se pela primeira vez os contornos do espaço no qual as ciências humanas serão alocadas. O espaço da analítica da finitude é determinado pela distribuição - ou melhor dizendo, pela reduplicação - que surge entre o nível das positividades (daquilo que se dá ao saber, isto é, do homem enquanto ser limitado) e aquele que diz respeito ao fundamental (daquilo que é condição de possibilidade do conhecimento). Ou seja: a analítica da finitude pavimenta o terreno no qual poderão se relacionar a reflexão fundacional de ordem filosófica e as ciências empíricas da vida, do trabalho e da linguagem: terreno no qual justamente se circularão as ciências humanas.

Em primeiro lugar, Foucault analisa o par formado pelas noções de empírico e transcendental. O homem é um duplo empírico-transcendental; ele dará margem para um campo de explicações concorrentes, quer se trate de fundamentar o conhecimento que ele tem na dimensão empírica (o que teria sido modelado a partir da estética transcendental kantiana) quer se trate ainda de buscar tal fundamentação em condições histórico-transcendentais (o que teria como modelo a dialética transcendental de Kant). Tais modelos - um, que ancora o conhecimento do homem em sua natureza, o outro que o vincula mais diretamente a seu 
estatuto de ser histórico - são nomeados por Foucault respectivamente como "positivista" e "escatológico". Sua flutuação e a tentativa de conjugá-los em uma fundamentação que assumisse ao mesmo tempo o empírico e o transcendental é o que constituiria, por exemplo, a análise do vivido - embora se trate, para Foucault, de um projeto incapaz de superar a ambiguidade que o gerou.

Em segundo lugar, o duplo entre cogito e impensado é da seguinte ordem: se o homem é reconhecido a partir de sua consciência, ele, por outro lado, é vislumbrado a partir de tudo aquilo que, o constituindo de forma não-consciente, não pode ser plenamente revelado por e para esta mesma consciência. Daí surge um caminho típico no saber moderno: a busca de retomar cada vez mais o que é impensado a partir da consciência; projeto que, se não se pode realizar jamais (posto que o impensado recua cada vez que se lhe tenta apreender), marca pela primeira vez uma interrogação ontológica sobre o homem: “Que é o ser do homem, e como poderia ocorrer que esse ser, que se poderia tão facilmente caracterizar pelo fato de que 'ele tem pensamento' e que talvez seja o único a possuí-lo, tenha uma relação indelével e fundamental com o impensado?" (FOUCAULT, 1981, p. 448).

Por fim, o terceiro duplo é aquele que se constitui entre o recuo e o retorno da origem. Ele pode ser examinado as partir da problemática da linguagem: nela, descobre-se que o homem é determinado por uma linguagem que recua sem cessar no tempo; que, por mais que se busque apreender a origem da linguagem, ela escapa. Todavia, por outro lado, se está separado da origem, "é sempre sobre um fundo do já começado que o homem pode pensar o que para ele vale como origem (FOUCAULT, 1981, p. 456). O homem retoma continuamente a origem, ao utilizar a linguagem que todavia tem um surgimento que sempre recua, ao determinar-se como ser do trabalho mesmo sem saber quando este surgiu, ao admitir-se enquanto ser vivo que surgiu em um momento sempre a encontrar.

\section{III}

A analítica da finitude desenha o terreno, o espaço configuracional da epistémê moderna, constituindo o palco no qual as ciências humanas poderão desempenhar seu papel. Falta apenas indicar que mais campo de saber participa desta configuração: trata-se das ciências formais. Foucault afirma que o desenho da epistémê moderna pode ser visto como um triedro: no qual os lados são constituídos pelas ciências empíricas da vida, do trabalho e 
da linguagem; pelo conjunto de reflexões fundamentadoras vislumbradas na analítica da finitude; e pelas ciências formais. O espaço próprio das ciências humanas compreende-se entre estes três, nos três planos que surgem a cada vez que uma destes lados é posto em relação com outro. Em, particular, ao se relacionar as ciências empíricas do homem com a analítica da finitude, tem-se a ideia de que o objeto das ciências humanas são as representações que se produzem a partir das análises próprias das ciências empíricas; representações que tematizam, por exemplo, não a vida, mas que se desenvolvem a partir do momento em que, na extensão dos processos fisiológicos que são um dos temas da biologia, o homem é visto como "esse ser vivo que, do interior da vida à qual pertence inteiramente e pela qual é atravessado em todo o seu ser, constitui representações graças às quais ele vive e a partir das quais detém esta estranha capacidade de poder se representar justamente a vida" (FOUCAULT, 1981, p. 487), e assim por diante.

Tais representações são orientadas no rumo da analítica da finitude. Uma longa citação permite explicitar mais convenientemente este ponto:

\begin{abstract}
As ciências humanas ocupam, pois, essa distância que separa (não sem uni-las) a biologia, a economia, a filologia daquilo que lhes dá possibilidade no ser mesmo do homem. [...] Elas reconduzem sub-repticiamente as ciências da vida, do trabalho e da linguagem, para o lado desta analítica da finitude que mostra como pode o homem haver-se, no seu ser, com as coisas que ele conhece e conhecer essas coisas que determinam, na positividade, seu modo de ser. Mas aquilo que a analítica requer na interioridade ou ao menos na dependência profunda de um ser que não deve sua finitude senão a si mesmo, as ciências humanas o desenvolvem na exterioridade do conhecimento. (FOUCAULT, 1981, p. 489).
\end{abstract}

Por isso, as ciências humanas encontram-se em uma posição reduplicadora, metaepistemológica (ou talvez, "hipo" ou "anaepistemológica") em relação às ciências empíricas, embrenhando o homem no campo "da finitude, da relatividade, da perspectiva - no campo da erosão indefinida do tempo" (FOUCAULT, 1981, p. 489).

Foucault passa assim a mapear o campo das ciências humanas, sugerindo que estas se distribuem em três regiões: a "região psicológica", no prolongamento da vida; a região "sociológica", que prolonga a dimensão do trabalho; a região extensiva à linguagem, que se pode observar, por exemplo, na análise dos mitos. Tal repartição, porém, lança dois problemas fundamentais: em primeiro lugar, qual é a positividade própria das ciências humanas, do ponto de vista de seus conceitos e de sua racionalidade própria? Em segundo lugar, como estas ciências lidam com a representação? 
Quanto à primeira questão, a resposta de Foucault se orientará no sentido de mostrar, primeiramente, que as polêmicas acerca da positividade nas ciências humanas ocorrem na medida em que tal positividade se apóia na transferência de modelos das ciências empíricas. Tais modelos podem ter o estatuto de metáforas (por exemplo, a metáfora do organismo); mas o que interessa a Foucault é indicar a importação de grandes categorias que, a seu ver, funcionam como modelos constituintes para as ciências humanas. Tais modelos são: de empréstimo à biologia, o modelo que se define a partir das categorias de "função" e "norma"; de empréstimo à economia, as categorias de "conflito" e "regra"; de empréstimo à teoria da linguagem, as categorias de "significação" e "sistema"; tais categorias organizam a psicologia (estudo do homem em termos de função e norma), a sociologia (estudo do homem em termos de conflito e regra) e a análise da literatura e dos mitos (estudo do homem em termos de significação e sistema).

O fato de que estes modelos se entrecruzam constantemente explica as discussões de método típicas das ciências humanas - e não a tão alardeada suposição de uma complexidade maior do “objeto-homem' em relação aos demais. Além disso, uma colocação em perspectiva histórica faz surgir um percurso no qual as ciências humanas são polarizadas, inicialmente, por um privilégio do biológico (que se percebe no período do romantismo e do positivismo); depois, por um privilégio do econômico (que se deixa notar por exemplo no pensamento de Marx); enfim, por um privilégio do modelo associado à linguagem (o par significação-sistema seria determinante para a compreensão do pensamento de Freud, por exemplo). No entanto, tal percurso é duplicado por aquele que fez recuar o primeiro termo dos pares que constitui cada modelo (fala-se das categorias de função, conflito e significação) em detrimento do segundo termo (norma, regra e sistema).

Podemos passar assim à questão acerca da representação. Foucault nega a ideia de que a passagem a este segundo momento (no qual as categorias em jogo parecem designar aquilo que seria menos manifesto, da ordem do inconsciente) teria representado um recuo da representação em prol de uma polarização em torno do inconsciente - afinal, embora um dos termos do par tenha passado a ser privilegiado, são os dois termos em conjunto que continuam a determinar a vida, o trabalho e a linguagem em termos representacionais. O privilégio dos "segundos termos" (norma, regra e sistema) significa, antes, na epistémê moderna, a dissociação entre o campo da consciência e o da representação, e "definem a maneira como as empiricidades podem ser dadas à representação, mas sob uma forma que não está presente à 
consciência" (FOUCAULT, 1981, pg. 502). De todo modo, as ciências humanas estão ainda alojadas na representação, que é seu suporte geral.

As ciências humanas, ao tratarem da representação como objeto, se esquecem de que ela é também sua condição de possibilidade, o que ocasiona algo que Foucault (1981) define como "mobilidade transcendental": ou seja, elas "não cessam de exercer para consigo uma retomada crítica. Vão do que é dado à representação ao que torna possível a representação, mas que é ainda uma representação" (idem, 504). Ou seja, quando os "segundos termos" passam a ter mais peso nos debates das ciências humanas, a consequência é que tais debates passam a ser circunscritos por análises que, partindo dos processos inconscientes, tematizam "normas, regras, conjuntos significantes que desvelam à consciência as condições de suas formas e de seus conteúdos" (ibid, pg. 505). É esta a especificidade das ciências humanas, que se liga sobretudo à disposição geral assumida pelo saber moderno - e não, mais uma vez, a uma pretensa superioridade do homem enquanto objeto.

Tal especificidade de localização permite a Foucault refutar as críticas que associam as ciências humanas a efeitos de superfície ou ilusões ideológicas - afinal, estas encontram-se definidas e delimitadas na epistémê moderna. Contudo, isso não significa uma afirmação da cientificidade às ciências humanas; ao contrário, Foucault sugerirá que, dentro do limiar de exigências que no saber moderno determina o que pode ser considerado ou não científico, as ciências humanas não preenchem formalmente tais requisitos; a disposição destas na epistémê moderna, enquanto lugares de trânsito entre ciências empíricas e analítica da finitude, atesta justamente isso.

É chegado o momento de encarar a questão que, desde o início deste texto, foi deixada em suspenso: trata-se da tão propalada morte do homem, que a nosso ver organiza em profundidade todo o escopo de As palavras e as coisas. Foucault atribuirá um lugar especial na epistémê moderna aos conhecimentos da História, da Psicanálise e da Etnologia. A História fraturada pela tensão entre historicidade constitutiva e saber historiográfico, pode ser considerada como campo privilegiado de disseminação de formas, métodos e escolhas de objeto das ciências humanas; mas ela é presa de uma oscilação permanente, que se exerce "entre os limites temporais que definem as formas singulares do trabalho, da vida e da linguagem, e a positividade histórica do sujeito que, pelo conhecimento, tem acesso a eles" (FOUCAULT, 1981, p. 515). 
Já a psicanálise e a etnologia (leia-se: a etnologia tal qual descortinada no contexto estruturalista) tem para Foucault o papel de fraturarem a organização do saber moderno, denunciando os limites e servindo como uma espécie de despertador que parece acordar lentamente esta epistémê de seu "sono antropológico" (a expressão é do próprio Foucault). Tomando como exemplo a psicanálise, esta parece atravessar a região que se estabelece entre, de um lado, a analítica da finitude e, de outro, as representações que constituem o objeto das ciências humanas, transpondo a estas representações no sentido de extravasá-las no rumo da finitude. Assim, ela descortina, a partir da vida e de suas funções e normas, a Morte; a partir dos conflitos e regras advindos da instância do trabalho, a abertura do Desejo; e, a partir das significações e sistemas da linguagem, a Lei. Sem que no entanto a psicanálise possa ou deva ser considerada uma espécie de teoria geral do homem; antes, ela deve ser como um espaço que, ao interrogar lucidamente a configuração moderna do saber, termina por levá-la a um impasse. Da mesma forma, a etnologia fará vacilar a epistémê moderna ao abrir seu campo de interrogação a outras culturas que, ao construírem historicidades diferenciais, relativizam a própria historicidade constitutiva do saber moderno.

Às duas dimensões descortinadas pela psicanálise e pela etnologia, Foucault agrega ainda a dimensão aberta pela linguística; em relação a estas, sugere que tais dimensões, em conjunto, apontam as próprias condições do homem enquanto noção organizadora - mas, perpetuamente instável - do saber, o que poderá ocasionar o fim do "sono antropológico" e a abertura de um novo campo epistêmico.

Foucault conclui seu trabalho lembrando que, do ponto de vista das configurações que o saber assumiu a partir do Renascimento, o homem não é necessariamente figura privilegiada; que talvez seu predomínio moderno já tenha se estendido por tempo demais; que campos limítrofes desta epistémê apontam para sua superação. Gilles Deleuze e Donna Haraway, seguindo a linha proposta por Foucault, sugerem de forma persuasiva que a atual disposição do saber agrega o homem a muitos outros objetos passíveis de uma codificação geral. Embora a obra de Foucault tenha seguido, a partir da "A Arqueologia do Saber", novas orientações que inclusive modificariam alguns termos das propostas apresentadas aqui (a colocação do saber enquanto elemento em dispositivos de saber/poder com um funcionamento de ordem estratégica é apenas uma destas modificações), não acreditamos que as possibilidades abertas pela teorização proposta na arqueologia do saber tenham já se esgotado. 


\section{REFERÊNCIAS}

DELEUZE, Gilles. Foucault. São Paulo: Brasiliense, 1995.

DREYFUS, Hubert \& RABINOW, Paul. Foucault: uma trajetória filosófica. Rio de Janeiro: Forense Universitária, 1995.

FOUCAULT, Michel. Naissance de la Clinique. Paris: P.U.F., 1963.

FOUCAULT, Michel. As Palavras e as Coisas. São Paulo: Martins Fontes, 1981.

FOUCAULT, Michel. A Arqueologia do Saber. Rio de Janeiro: Forense Universitária, 1997. 